\title{
Effect of teaching strategies on adherence to antiepileptic drugs and recurrence of seizures among epileptic patients
}

\author{
Asmaa Sayed Abd-Almageed*, Marwa Ali Almasry \\ Faculty of Nursing, Assiut University, Assiut, Egypt
}

Received: September 5, 2018

Accepted: November 20, 2018 Online Published: November 29, 2018

DOI: $10.5430 /$ jnep.v9n4p8

URL: https://doi.org/10.5430/jnep.v9n4p8

\begin{abstract}
Background and objective: Adherence to medications is the backbone to effectiveness of a treatment. Adherence to antiepileptic drugs (AEDs) is essential to prevent the risk of seizures recurrence. The aims were to study the effect of teaching strategies on adherence to antiepileptic drugs, recurrence of seizures, and identify factors affecting the adherence level among epileptic patients.

Methods: Research design: Quasi-experimental design. Setting: Neurology Department at Neurological and Psychiatric Assiut University Hospital. Sample: A purposive sample of sixty male and female adult patients diagnosed with epilepsy. Tools: Tool I-Patient assessment sheet. Tool II-Morisky Medication Adherence Scale. Tool III-Liverpool Seizure Severity Scale.

Results: There was a statistically significant difference between pre and post applying of teaching strategies as regard drug adherence and recurrence of seizures among epileptic patients $(p<.001)$. Also, forgetfulness, side effects of medications, and absence of family or friend were the main factors of non- adherence to AEDs.

Conclusions and recommendations: Teaching strategies had statistical significant effects on adherence to antiepileptic drugs and on reducing recurrence of seizures among epileptic patients. Simple educational pamphlet for epileptic patients and their family members to improve adherence to AEDs should be available in Neurology Department and Outpatient Neurology Clinics.
\end{abstract}

Key Words: Adherence, Antiepileptic drugs, Epileptic patients, Teaching strategies

\section{INTRODUCTION}

Epilepsy is the most common serious neurological disorder worldwide. It affects all age-groups and all geographic boundaries; although this condition remits in some people, many will have epilepsy through their lives. ${ }^{[1]}$ Antiepileptic drugs (AEDs) are the primary treatment for epilepsy. AEDs are symptomatic treatments that decrease seizure occurrence and severity but do not alleviate the course of the disorder. ${ }^{[2]}$

Uncontrolled seizures result in major morbidity and mortality, including physical injury, for example head injury, fractures and burns, and psychosocial problems, for example depression, anxiety disorders, reduced quality of life, and sudden unexpected death. ${ }^{[3]}$

Factors that usually hamper the success of AEDs may be biological or non-biological in nature; these factors include poor drug adherence, drug resistance, drug-drug interactions and drug cost. The effectiveness of AEDs is imperfect if the patient does not adhere to the treatment regimen. The general estimates of epileptic patients' adherence to medication regimens differ in course and level. ${ }^{[4,5]}$

*Correspondence: Asmaa Sayed Abd-Almageed; Email: dr_es_sa@yahoo.com; Address: Faculty of Nursing, Assiut University, Assiut, Egypt. 
The term adherence refers to the extent to which patients taking their medications as prescribed with respect to dose and dosing intervals. ${ }^{[6]}$ The term non-adherence describes the following aspects in its definition: not taking the right dosage, not leaving the recommended length of time among doses, not taking medications for the duration specified, or taking other drugs not prescribed. Some physicians believe that any patient fails to adhere on one time or more is noncompliant whereas others believe that only those who fail to comply at least $25 \%$ of the time should be classified as non-compliant. ${ }^{[7]}$

Non-adherence to medication regimens is a world- wide health problem. The rates of non-adherence among epileptic patients range from $30 \%$ to $50 \%$. Physicians treating epileptic patients note that non-adherent patients report more difficult in attaining seizure control compared to adherent patients. ${ }^{[8]}$

AEDs non adherence is one modifiable factor contributing to continued seizures. It also contributes to other significant health and financial ramifications, such as uninformed clinical decision-making, increased seizure severity and frequency, health-care costs, increased incidence of emergency room visits, hospitalization, motor vehicle injuries, and fractures. ${ }^{[9]}$ Seizure risk is $21 \%$ higher among non-adherent patients than adherent patients. ${ }^{[10]}$

In fact, patient education is an important aspect in enhancing adherence. It can be seen as the base for the majority of patients-core intervention and can develop their motivation to comply with the therapeutic regimen. So, teaching and counseling patients about importance of adherence to AEDs is just as vital to their recovery. Patients' education to strictly follow medication regimens is the key to epilepsy treatment. $^{[3]}$

Nurse is the provider of direct care to patients; nurses are also responsible for teaching patients about their medical conditions and the potential impact on their lives. Nurses offer a unique perspective in the early education of epileptic patients. As a part of the health-care team, the nurse plays an important role in providing comprehensive epilepsy education. ${ }^{[11,12]}$

\subsection{Significance of the study}

The prevalence of epilepsy is 6.4 cases per 1,000 persons and the annual incidence is 67.8 cases per 100,000 persons, according to a meta-analysis of international studies. ${ }^{[13]}$ In Egypt, the prevalence was estimated to be $6.98 / 1,000 .^{[14]}$ According to records of neurology department at Neurological and Psychiatric Assiut University Hospital in year 2017, 300 cases was recorded and diagnosed as epilepsy. Also, from the researchers' experiences, it was noted that patients' knowledge about importance of adherence to AEDs are inadequate and need for improvement. Therefore the current study is considered the first one in this geographical location to help patients improving their adherence to AEDs and reduce recurrence of seizures.

\subsection{Aim of the study}

The aims of the study were to study the effect of teaching strategies on adherence to antiepileptic drugs, recurrence of seizures, and identify factors affecting the adherence level among epileptic patients.

\subsection{Research hypothesis}

After applying teaching strategies, the studied patients will show more adherence to antiepileptic drugs and reduce recurrence of seizures than before applying teaching strategies.

\section{Patients And method}

\subsection{Research design}

Quasi-experimental design was utilized, which is a type of evaluation which aims to determine if a program or intervention has an intended effect on a study's participants. ${ }^{[15]}$

\subsection{Study variables}

The independent variable was the teaching strategies, while the dependent variables were adherence to antiepileptic drugs and recurrence of seizures.

\subsection{Setting of the study}

The study was conducted in Neurology Department at Neurological and Psychiatric Assiut University Hospital.

\subsection{Sample}

Inclusion criteria: A purposive sample of 60 male and female adult patients diagnosed with epilepsy, their age ranged from 18 to 65 years, willing to participate in the study, and free from cognitive impairment or psychiatric disorders. The sample was calculated by using power analysis according to the patients flow with precision levels $5 \%$ at confidence level $95 \%$ and $p<.05$.

\subsection{Exclusion criteria}

Presence of progressed neurological or medical disorders, history of psychiatric disorders that could limit participation, and history of substance abuse within the last year.

\subsection{Tools}

Tool I: Patient assessment sheet, this tool was developed by researchers to assess demographic data, medical data, and 
factors affecting the adherence level among epileptic patients. It included two parts:

Part 1: Demographic and medical data

- Demographic data: Patient name, age, sex, residence, marital status, educational level, and occupation.

- Medical data: Family history of epilepsy, duration of epilepsy by years, type of seizure, and number of epilepsy attack (this item assessed pre and post application of teaching strategies).

Part 2: Factors affecting adherence to antiepileptic drugs

This part contains 10 questions about factors affects adherence to antiepileptic drugs, which included (Forgetfulness, unawareness of the importance of adherence to treatment, preoccupation with life, absence of the family members or friends, high medicine price, medications side effects, duration of treatment, medication complexity, repeated treatment more than once a day, and non-availability of medication).

Tool II: Morisky Medication Adherence Scale (MMAS-8)

It was developed by Morisky et al. (2008). ${ }^{[16]}$ It is used for assessing patients' adherence level to AEDs. Eight questions were used for evaluating the patients' forgetfulness; patients' understanding of the need for continued medications and if the patient felt it was inconvenient adhering to a daily treatment plan.

Scoring system: A score of zero was given for a positive response while a score of one was given for a negative response for questions 1, 2, 3, 4, 6 and 7 (Yes $=0$; No = 1). Contrariwise, for item 5 , a score of zero was given for a negative response while a score of one was given for a positive response (Yes $=1 ;$ No $=0$ ). For item 8 , a score of one was given for 'Never/Rarely' while a score of zero was given for 'Once in a while/Sometimes/Usually/All the time'. The total score was eight. Patients who had a score of 8 were considered to have good adherence level while patients who had a score of less than 8 were considered having a poor adherence level. It was adopted by the researcher to assess patient's adherence to AEDs.

\section{Tool III: Liverpool Seizure Severity Scale (LSSS)}

It was developed by Baker et al. (1998) ${ }^{[17]}$ to assess the severity of a patient's seizures during the past four weeks. It consists of 2 subscales: perception of control and ictal and postictal effects. It consists of 20 items rated on a 4 point Likert scale.

Scoring system: The response categories for scale items include:

Items I-4, 6, 7, 13-18 and 20: (always, usually, sometimes, never). Item 5 (very good, fairly good, little control, no control). Item 8 (all of them, lot of them, few of them, none of them). Item 9 (very severe, severe, mild, very mild). Item 11 (very confused, fairly confused, slightly confused, not at all confused). Items 10 and $12(<1 \mathrm{~min}, 1-2 \mathrm{~min}, 2-5 \mathrm{~min},>5$ min). Item 19 (<1 $\mathrm{min}, 1-5 \mathrm{~min}, 6-60 \mathrm{~min},>60 \mathrm{~min}$ ).

The higher scores indicating more severe seizures. It was adopted by the researchers to assess the severity of seizures during the past four weeks.

\subsection{Ethical considerations}

Permission to carry out the study was obtained from the ethical committee of the Faculty of Nursing and from the hospital authorities of Neurology Department at Neurological and Psychiatric Assiut University Hospital. Prior to the initial interview, the researchers introduced themselves to patients. Oral agreement for voluntary participation was obtained. Anonymity and confidentiality were assured through coding of the data. The patients had the right to refuse to participate in the study and can withdraw at any time.

\subsection{Content validity}

It was established by a panel of five experts (three experts from Medical Surgical Nursing staff and two Neurology staff) who reviewed the tool for clarity, relevance, comprehensiveness, understanding, and applicability. Minor modifications were required. Test reliability of the proposed tools was ascertained with Cronbach's alpha $=0.90$.

\subsection{Pilot study}

It was implemented on $10 \%$ of the sample (six patients), to find out the feasibility of the study, and identify any difficulties needed to be handled. No changes were done to the tools, so the sample of the pilot study was included in the actual study sample.

\subsection{Teaching strategies}

Patients received several adherence improving strategies to AEDs. Patients were counseled on the goals of anticonvulsant drugs and the importance of good adherence in achieving these goals, a schedule of medications-taking was devised that corresponded with the patient's daily habits, information on the name of the antiepileptic medication, its color, shape and strength, the therapeutic effect, dosage, precautions and possible unwanted effects. Each patient connecting the intention of taking medication with a specific time each day (when eating, brushing teeth, or doing other daily activities), use a weekly fill box (separate compartments for each day or time of day), use calendar or remember chart, have a family member or friend remind patient. Experts in fields of neurology checked the content for comprehensiveness, clarity, 
relevancy and applicability and corrections were carried out accordingly. Each patient was given a copy of an educational pamphlet.

\subsection{Procedure}

The study proceeded using the following phases:

1) Assessment phase:

The researchers met the selected patients; each patient was fully informed with the purpose and nature of this study and the patients' agreement was obtained. Base line data were established using tool I (part 1), assessment of adherence to antiepileptic drug using (tool II), factors affects adherence to antiepileptic drugs were assessed tool I (part 2), then severity of a patient's seizures in last month was assessed using (tool III).

2) Implementation phase:

- The studied patients were given an educational pamphlet in clear Arabic language, which included teaching strategies; each patient was met for one session. Each session took about 30-40 min. The study was carried out in the morning shift.

- Teaching strategies were applied on an individual basis. One of the family members attended the session to confirm patient support and increasing their sense of responsibility.

- After each session there was 5-10 minutes for discussion and feedback. Reinforcement was performed according to patients' needs to ensure understanding. The researcher used pictures and diagram to help them retain the learned material.

- Data were assured anonymity and confidentiality and were collected using the study tools.

- The researchers arranged with the patients the time and place for follow up which were after one month in the Outpatient Clinics of Neurological and Psychiatric Assiut university hospital.

- This study was carried out through the period from September 2017 to May 2018 at morning shift.

3) Evaluation phase:

- In this phase, patients were reassessed after one month using the same tools; number of attack was reassessed using tool I (part 2). Also, adherence to antiepileptic drug and severity of a patient's seizures was assessed using (tool II and III).

- Studied patients attended the follow-up sessions in the Outpatient Clinics of Neurology to evaluate the effectiveness of the teaching strategies. The session took about 30 minutes.

\subsection{Statistical analysis}

Date entry and analysis were done using SPSS version 19. Data were presented as number, percentage, mean, median and standard deviation. Fisher exact test was used to compare qualitative variables. Mann-Whitney test was used to compare quantitative variables. Wilcoxon Signed Rank Test was done to compare quantitative variables between pre-test and post-test. Spearman correlation was done to measure correlation between quantitative variables. $p$-value considered statistically significant when $p<.05$.

\section{RESUlts}

Table 1 shows that the highest percentage of the studied patients their ages ranged between $31-40$ years old, with a mean age of $35.97 \pm 10.49$ and the highest percentage of them was male $(61.7 \%)$, married $(60 \%)$ and from rural area $(71.7 \%)$. Concerning the educational level, $(70 \%)$ of studied patients had secondary level of education. In relation to patients' occupation, the highest percentages of the studied patients $(65.0 \%)$ were not work.

Table 1. Frequency distribution of demographic characteristics of the studied patients $(n=60)$

\begin{tabular}{|c|c|c|}
\hline Characteristics & $\mathbf{N}$. & $\%$ \\
\hline \multicolumn{3}{|l|}{ Age (years) } \\
\hline $21-30$ & 21 & 35.0 \\
\hline $31-40$ & 23 & 38.3 \\
\hline$>40$ & 16 & 26.7 \\
\hline Mean \pm SD (Range) & \multicolumn{2}{|c|}{$35.97 \pm 10.49(21.0-60.0)$} \\
\hline \multicolumn{3}{|l|}{ Sex } \\
\hline Male & 37 & 61.7 \\
\hline Female & 23 & 38.3 \\
\hline \multicolumn{3}{|l|}{ Marital status } \\
\hline Single & 20 & 33.3 \\
\hline Married & 36 & 60.0 \\
\hline Divorced & 4 & 6.7 \\
\hline \multicolumn{3}{|l|}{ Residence } \\
\hline Rural & 43 & 71.7 \\
\hline Urban & 17 & 28.3 \\
\hline \multicolumn{3}{|l|}{ Educational level } \\
\hline Primary & 6 & 10.0 \\
\hline Preparatory & 6 & 10.0 \\
\hline Secondary & 42 & 70.0 \\
\hline Illiterate & 6 & 10.0 \\
\hline \multicolumn{3}{|l|}{ Occupation } \\
\hline Farmer & 5 & 8.3 \\
\hline Employee & 3 & 5.0 \\
\hline Skilled worker & 8 & 13.3 \\
\hline Unskilled worker & 3 & 5.0 \\
\hline Free business & 2 & 3.3 \\
\hline Does not work & 39 & 65.0 \\
\hline
\end{tabular}

Table 2 reveals that $81 \%$ of the studied patients had negative 
family history for epilepsy. More than one third (38\%) their duration of epilepsy ranged between 15-20 years with a mean $17.78 \pm 9.32$. In relation to type of seizure, the results show that the most of patients $(96.7 \%)$ had generalized seizure.

Table 2. Frequency distribution of medical data of the studied patients $(n=60)$

\begin{tabular}{llc}
\hline Variables & $\mathbf{N}$ & \% \\
\hline Family history of epilepsy & & \\
Positive & 11 & 18.3 \\
Negative & 49 & 81.7 \\
Duration of epilepsy by years & & \\
$<15$ & 19 & 31.7 \\
$15-20$ & 23 & 38.3 \\
$>20$ & 18 & 30.0 \\
Mean \pm SD (Range) & $17.78 \pm 9.32(2.0-40.0)$ \\
Type of seizure & & \\
Generalized & 58 & 96.7 \\
Partial & 2 & 3.3 \\
\hline
\end{tabular}

Table 3 reflects that there was highly statistically significant improvement in the mean seizure severity scores among the studied patients in post application of teaching strategies than before $(p<.0001)$.

Table 4 clarifies that, the most common factors affect on anti-epileptic drug adherence were forgetfulness (95\%), absence of the family members or friends $(65 \%)$, side effect of medications $(65 \%)$.

Table 5 shows that there was highly statistically significance difference between pre and post application of teaching strategies regards number of attack.

Table 6 reflects that there was a statistically significant improvement in the mean seizures severity scores among the studied patients post application of teaching strategies than before.

Table 7 shows that there was a statistical significance difference between number of seizure attack recurrence and level of adherence post application of teaching strategies.

Figure 1 shows that there was a significant negative correlation between seizures severity score and Morsky score $(r=$ $-0.673, p=.001)$. So, with increasing the adherence to AEDs there is a decrease in the severity of seizures.

Table 3. Drug adherence pre and post application of teaching strategies according to Morisky Medication Adherence Scale $(\mathrm{n}=60)$

\begin{tabular}{|c|c|c|c|c|c|}
\hline \multirow{2}{*}{ Morsky scale } & \multicolumn{2}{|c|}{ pre application of teaching strategies } & \multicolumn{2}{|c|}{ Post application of teaching strategies } & \multirow{2}{*}{$p$-value } \\
\hline & No. & $\%$ & No. & $\%$ & \\
\hline Poor adherence & 60 & 100.0 & 20.0 & 33.0 & \multirow{2}{*}{$.0001 * * *$} \\
\hline Good adherence & 0 & 0.0 & 40.0 & 66.7 & \\
\hline
\end{tabular}

***Highly Significant $p<.001$.

Table 4. Factors affecting on the antiepileptic drugs adherence among studied patients $(\mathrm{n}=60)$

\begin{tabular}{|c|c|c|}
\hline Risk factors & N. & $\%$ \\
\hline Forgetfulness. & 57 & 95.0 \\
\hline Unawareness the importance of adherence to treatment. & 26 & 43.3 \\
\hline Preoccupation with life. & 20 & 33.3 \\
\hline Absence of the family member or friend who help you to remind taking the medications on time. & 39 & 65.0 \\
\hline High medicine price. & 32 & 53.3 \\
\hline Medications side effect. & 39 & 65.0 \\
\hline Duration of treatment. & 22 & 36.7 \\
\hline Medication complexity. & 32 & 53.3 \\
\hline Repeat treatment more than once a day. & 28 & 46.7 \\
\hline Non-availability of medication. & 13 & 21.7 \\
\hline
\end{tabular}

Table 5. Number of attack recurrence pre and post application of teaching strategies $(n=60)$

\begin{tabular}{|c|c|c|c|}
\hline Number of attack recurrence & Pre application of teaching strategies & Post application of teaching strategies & $p$-value \\
\hline Mean \pm SD & $3.05 \pm 0.75$ & $0.93 \pm 1.44$ & \multirow{2}{*}{$.0001 * * *$} \\
\hline Median (Range) & $3.0(2.0-4.0)$ & $0.0(0.0-4.0)$ & \\
\hline
\end{tabular}


Table 6. The mean seizures severity score in pre and post application of teaching strategies according to Liverpool Seizure Severity Scale $(n=60)$

\begin{tabular}{llll}
\hline Seizures severity score & Pre application of teaching strategies & Post application of teaching strategies & $p$-value \\
\hline Mean \pm SD & $56.92 \pm 6.72$ & $28.15 \pm 9.49$ & $.001^{* *}$ \\
Median (Range) & $58.0(39.0-68.0)$ & $24.0(21.0-52.0)$ & \\
\hline
\end{tabular}

**Significant $p<.01$.

Table 7. Relation between number of seizure attack recurrence and level of adherence post application of teaching strategies

\begin{tabular}{llll}
\hline \multirow{2}{*}{ Number of attack recurrence } & \multicolumn{2}{l}{ Morsky scale post } & Good adherence \\
\cline { 2 - 3 } & Poor adherence & \\
\hline Post-test & $2.15 \pm 1.73$ & $0.33 \pm 0.73$ & $.001^{* *}$ \\
Mean \pm SD & $3.0(0.0-4.0)$ & $0.0(0.0-2.0)$ & \\
Median (Range) &
\end{tabular}

**Significant $p<.01$.

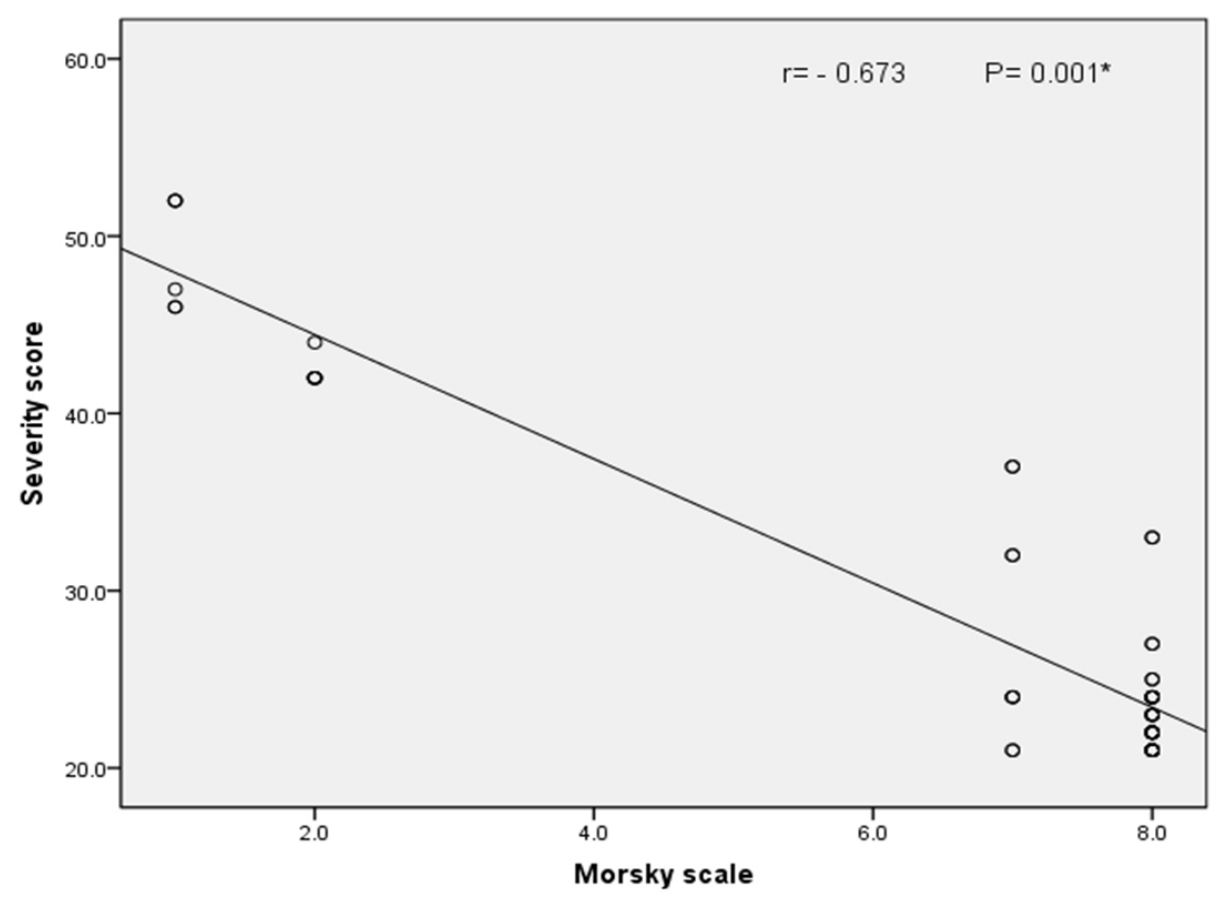

Figure 1. Correlation between seizure severity score and Morsky score

\section{Discussion}

Epilepsy is the third leading contributor to the global burden of disease for neurological disorders and affects 65 million people world-wide. ${ }^{[18]}$

Regarding demographic data the present study presented that the highest percentage of the studied patients was 31-40 years old and this comes in line with Molugulu et al. (2016) ${ }^{[19]}$ who found the same result in their study about "Medication adherence and its associated factors among epilepsy patients".

Published by Sciedu Press
Regarding sex, more than half of the studied patients were male and this agreed with Jhussein and Qaderi (2002) ${ }^{[20]}$ in their study about socio-demographic characteristics of adolescents with epilepsy, they found that the male to female ratio was 54:47. But this result didn't agree with Mohammed $(2018)^{[21]}$ who stated that more than half of the study group was females.

Regarding residence and occupation, about two third of the current study living in rural area and are not working, this in line with Shawki (1996) ${ }^{[22]}$ who reported that the high- 
est prevalence rate of epilepsy in rural areas was observed among the group who do not work.

Regarding family history of epilepsy, the current study revealed that the majority of the studied patients had negative family history, this result supported by Shorvon (2011) ${ }^{[23]}$ who demonstrated that genetic cause of epilepsy of most cases remains ambiguous.

Regarding adherence to AEDs, our results revealed that there is a significance difference between pre and post application teaching strategies, from the researchers point of view this may be due to containment of the teaching strategies with the all needed methods that help in AEDs adherence, using of pictures and diagram in discussion helped the patients to retain the learned material, also follow-up of studied patients by the researchers to ensure commitment of the patients to implement the teaching strategies.

Similar with the current study Al-aqeel and Al-sabhan $(2011)^{[24]}$ stated that education and counseling of patients with epilepsy have shown mixed success and added that behavioral interventions such as the use of intensive reminders and implementation intention interventions provided more positive effects on AEDs adherence.

Similar with the current study, a study done in Kelantan, Malaysia by Shaaban (2011) ${ }^{[25]}$ the result showed that more than half of epileptic patients did not comply with their drugs regime in using the self reported method. Also MakmorBakry et al. (2015) ${ }^{[26]}$ reported that the prevalence of poor adherence to AEDs among epileptic patients in the study group was $64.1 \%$.

Also, Peterson et al. (1984) ${ }^{[27]}$ supported the current study results as they reported that the use of patient reminders, such as mailed reminders for prescription refill and appointments together with a counseling leaflet, was found to produce promising effects on adherence.

Regarding factors affecting AEDs adherence, the current study showed that forgetfulness, side effects of medication, absence of family or fiend support, medication complexity, unawareness the importance of adherence to AEDs and preoccupation with life were factors leading to non-adherence to prescribed AEDs. From the researchers' point of view this may be due to unawareness of patients the importance of medication, the long treatment duration might compromise patients' beliefs about medication effectiveness, also, patients hadn't knowledge about different methods to remember taking AEDs at the same time with the same dose.

Ferrari et al. (2013) ${ }^{[28]}$ agreed with current study and stated that, the most common reasons for non-adherence to treat- ment regimens were forgetting to take the medication, and lack of time to take medications, but they did not find an association between friends and family support and adherence. Also, Getachew et al. (2014) ${ }^{[29]}$ presented in their study that most common reasons for missing dose were forgetfulness followed by being busy.

In this regard Makmor-Bakry et al. (2015) ${ }^{[26]}$ studied factors affecting adherence to antiepileptic drugs in Malaysia, results showed that factors associated with poor adherence to AEDs were, medication side effects and uncertainty about the necessity for AEDs. Sweileh et al. (2011) ${ }^{[30]}$ found that more than half of the epileptic patients thought that they could decrease or stop taking the AEDs just to see what would happen.

Also, Bano and Numanb (2016) ${ }^{[31]}$ stated in their study that drugs complexity (more than two antiepileptic drugs), and treatment duration ( $>6$ months) were major factors that affected adherence.

Regarding number and severity of seizures attack, the current study showed that there was a statistically significance difference between pre and post application of teaching strategies. Also a significant positive correlation was found between seizure severity and poor adherence; from the researchers' point of view this may be due to increase awareness of patients to the importance of AEDs adherence, and using of teaching strategies which helped those patients to be more adherent.

Similar with the current study, Jones et al. (2006) ${ }^{[32]}$ reported that poor treatment adherence is strongly associated with uncontrolled seizures among patients with epilepsy, and with symptoms recurrence in other chronic diseases, also Hovinga et al. (2008) ${ }^{[33]}$ found non-adherence to be associated with reduced seizure control.

Similarly, Peterson et al. (1984) ${ }^{[27]}$ compared the number of seizures between study and control groups at follow up and found that the reduction in seizure frequency from baseline was significant for the study group but not significant for the control group.

Contrary to this study Helgeson et al. (1990) ${ }^{[34]}$ stated that seizure frequencies were reported to be not significantly changed from baseline to follow up in both the study and control groups.

\section{Conclusion}

Teaching strategies had statistical significant effects on adherence to antiepileptic drugs and on reducing recurrence of seizures among epileptic patients. 


\section{Recommendations}

(1) Physicians should be made aware that prescription of less complex medication regimens may result in better treatment adherence, and therefore better seizure control.

(2) Simple educational pamphlet for epileptic patients and their family members to improve adherence to AEDs should be available in Neurology Department and Outpatient Neurology Clinics.

\section{CONFlicts OF InTEREST Disclosure}

The authors declare that there is no conflict of interest.

\section{REFERENCES}

[1] Stafstrom CE, Miller JW, Goodkin HP. Recognizing seizures and epilepsy: insights from pathophysiology. In: Epilepsy, Wiley Blackwell, Hoboken. 2014; 3-9.

[2] Pitkänen A. Therapeutic approaches to epileptogenesis-hope on the horizon. Epilepsia. 2010; 51: 2-17. PMid:20618393 https: //doi.org/10.1111/j.1528-1167.2010.02602.x

[3] Smithson WH, Hukins D, Colwell B, et al. Developing A method to identify medicines non-adherence in a community sample of adults with epilepsy. Epilepsy Behavior. 2012; 24: 49-53. PMid:22494797 https://doi.org/10.1016/j.yebeh.2012.02.015

[4] Kwan P, Schachter SC, Brodie MJ. Drug-Resistant epilepsy. N Engl J Med. 2011; 365: 919-2. PMid:21899452 https://doi .org/10 .1056/NEJMra1004418

[5] Chapman D, Panelli R, Hanna J, et al. Sudden unexpected death in epilepsy. Continuing the global conversation. Epilepsy Australia Ltd., Australia, 2011.

[6] Cramer JA, Roy A, Burrell A, et al. Medication compliance and persistence: terminology and definitions. Value in Health. 2008; 11(1): 44-7. PMid: 18237359 https://doi.org/10.1111/j.1524-473 $3.2007 .00213 . x$

[7] Liu J, Liu Z, Ding H, et al. Adherence to treatment and influencing factors in a sample of Chinese epilepsy patients. Epileptic Disorders. 2013; 15(3): 289-94.

[8] Dillorio C, Shafer PO, Letz R, et al. Project EASE: a study to test a psychosocial model of epilepsy medication management. Epilepsy Behaviour. 2004; 5: 926-36. https://doi.org/10.1016/j.ye beh.2004.08.011

[9] Modi AC, Wu YP, Guilfoyle SM, et al. Uninformed clinical decisions resulting from lack of adherence assessment in children with new onset. 2012.

[10] Manjunath R, Davis KL, Candrilli SD, et al. Association of antiepileptic drug non adherence with risk of seizures in adults with epilepsy. Epilepsy \& Behavior. 2009; 14(2): 372-8. PMid:19126436 https : //doi.org/10.1016/j.yebeh.2008.12.006

[11] Larsen J. Correct use of drugs in elderly in nurse home and home care service within the municipality of Troms. Development Center for nurse home and home care service, Troms: 2012 by Ellie Williams (Role of Patient Teaching for the Professional Nurse).

[12] Hausman SV, Luckstein RR, Zwygart AM, et al. Epilepsy Education: A Nursing Perspective. Mayo Foundation for Medical Education and Research. 1996; 71(11): 1114-1117.

[13] Fiest KM, Sauro KM, Wiebe S, et al. Prevalence and incidence of epilepsy: a systematic review and meta-analysis of international studies. Neurology. 2017; 88: 296-303. PMid:27986877 https: //doi.org/10.1212/WNL.0000000000003509

[14] El Tallawy HN, Farghaly WM, Metwaly NA, et al. Door-to-door survey of major neurological disorders in Al Kharga District, NewValley,
Egypt: methodological aspects. Neuroepidemiology. 2010; 35: 185190. PMid:20664292 https ://doi .org/10.1159/000314345

[15] Burns N, Grove SK. Understanding Nursing Research. 4th ed. Philadelphia, PA: W. B. Saunders. 2007.

[16] Morisky D, Ang A, Krousel-Wood M, et al. Predictive Validity of a Medication Adherence Measure for Hypertension Control Journal of Clinical Hypertension. 2008; 10(5): 348-354. https: //doi.org/10.1111/j.1751-7176.2008.07572.x

[17] Baker GA, Smith DF, Jacoby A, et al. Liverpool Seizure Severity Scale revisited. Seizure. 1998; 7(3): 201-5. https ://doi .org/10 .1016/S1059-1311 (98) 80036-8

[18] Vos T, Allen C, Arora M, et al. A systematic analysis for the global burden of disease study. The lancet. 2016; 388(10053): 1545-1602.

[19] Molugulu N, Gubbiyappa KS, Vasudeva Murthy CR, et al. Evaluation of self reported medication adherence and its associated factors among epilepsy patients in Hospital Kuala Lumpur. Journal of Basic and Clinical Pharmacy. 2016; 7(4): 105-9. PMid:27999469 https://doi.org/10.4103/0976-0105.189430

[20] Jhussein M, Qaderi S. Socio-demographic characteristics of adolescents with epilepsy in Northern Jordan. European Journal of Epilepsy. 2002; 11(8): 483-488. https://doi.org/10.1016/S1059-131 1 (02) 00133-4

[21] Mohammed SH. Effect of Lifestyle Modification on Epileptic Patients Outcomes. Submitted for fulfillment of the requirements for Doctorate Degree in Medical Surgical Nursing, Faculty of nursing, Assiut University; 2018.

[22] Shawki AO. Clinico-epidemologic study of epilepsy in Assiut. Submitted for fulfillment of the requirements of Doctorate Degree in neurology, Faculty of medicine, Assiut University; 1996.

[23] Shorvon SD. The causes of epilepsy: Changing concepts of etiology of epilepsy over the past 150 years. Medical Devices and Sensors. 2011; 52(6): 1033-1044.

[24] Al-aqeel S, Al-sabhan J. Strategies for improving adherence to antiepileptic drug treatment in patients with epilepsy. Cochrane Database of Systematic Reviews. 2011.

[25] Shaaban J, Ishak H, Ismail AH. Factors associated with drug compliance among epilepsy patients. Int Med J. 2011; 18: 78.

[26] Makmor-Bakry M, Lau CL, Raymond AA. Factors affecting adherence to antiepileptic drugs therapy in Malaysia. Neurology Asia. 2015; 20(3): 235-241.

[27] Peterson GM, Mc Lean S, Millingen KS. A randomized trial of strategies to improve patient compliance with anticonvulsant therapy. Epilepsia. 1984; 25(4): 412-7. https://doi.org/10.1111/j.15 28-1157.1984.tb03436.x

[28] Ferrari CM, Cardoso RM, Luiz HM. Factors associated with treatment non-adherence In patients with epilepsy in Brazil. European Journal of Epilepsy. 2013; 22(5): 384-389. PMid:23478508 https : //doi.org/10.1016/j.seizure.2013.02.006 
[29] Getachew H, Dekema NH, Awol SS, et al. Medication adherence in epilepsy and potential risk factors associated with non- adherence in tertiary care teaching hospital in southwest Ethiopia. Gaziantep Med J. 2014; 20(1): 59-65. https://doi .org/10.5455/GMJ-30-459 04

[30] Sweileh WM, Ihbesheh MS, Jarar IS. Self-reported medication adherence and treatment satisfaction in patients with epilepsy. Epilepsy Behave. 2011; 21: 301-5. PMid:21576040 https: //doi.org/10 $.1016 / j$. yebeh .2011 .04 .011

[31] Bano S, Numanb A. Factors influencing antiepileptic drug noncompliance in epileptic patients of Pakistan. Pakistan Journal of Neurological Sciences (PJNS). 2016; 11(1): Article 5.

[32] Jones RM, Butler JA, Thomas VA, et al. Adherence to treatment in patients with epilepsy: associations with seizure control And illness beliefs. Seizure. 2006; 15: 504-8. PMid:16861012 https: //doi.org/10.1016/j.seizure.2006.06.003

[33] Hovinga CA, Assato MR, Manjunath R, et al. Association of nonadherence to antiepileptic drugs and seizures, quality of life, and productivity: survey of patients with epilepsy and physicians. Epilepsy Behaviour. 2008; 13: 316-22. PMid:18472303 https://doi.org/ $10.1016 / j$. yebeh 2008.03 .009

[34] Helgeson DC, Mittan R, Tan SY, et al. Sepulveda Epilepsy Education: the efficacy of a psycho educational treatment program in treating medical and psychosocial aspects of epilepsy. Epilepsia. 1990; 31(1): 75-82. https://doi .org/10.1111/j.1528-1157. 1990.tb05363.x 